$40(1) \mid 2011$

Varia

\title{
Nuevas centralidades y acceso a la ciudad en las periferias bogotanas
}

Nouvelles centralités et accès à la ville dans les secteurs périphériques de Bogotá News centralities and Access to the city in peripheral areas of Bogota

\section{Alice Beuf}

\section{OpenEdition}

\section{Journals}

Edición electrónica

URL: http://journals.openedition.org/bifea/1663

DOI: 10.4000/bifea.1663

ISSN: 2076-5827

Editor

Institut Français d'Études Andines

Edición impresa

Fecha de publicación: 1 abril 2011

Paginación: 147-178

ISSN: 0303-7495

\section{Referencia electrónica}

Alice Beuf, « Nuevas centralidades y acceso a la ciudad en las periferias bogotanas », Bulletin de I'Institut français d'études andines [En línea], 40 (1) | 2011, Publicado el 01 octubre 2011, consultado el 06 noviembre 2020. URL : http://journals.openedition.org/bifea/1663 ; DOI : https://doi.org/10.4000/ bifea.1663

\section{(c) (†) $\ominus$}

Les contenus du Bulletin de l'Institut français d'études andines sont mis à disposition selon les termes de la licence Creative Commons Attribution - Pas d'Utilisation Commerciale - Pas de Modification 4.0 International. 


\title{
Nuevas centralidades y acceso a la ciudad en las periferias bogotanas
}

\author{
Alice Beuf*
}

\section{Resumen}

Las transformaciones territoriales de los sectores periféricos de Bogotá han impulsado el surgimiento de lugares con atributos de centralidad. Así, en el Plan de Ordenamiento Territorial (2000), los planificadores señalan el papel de las centralidades urbanas en la integración de los espacios periféricos socialmente desfavorecidos. Este texto examina si las transformaciones territoriales reales coinciden con el modelo concebido por los planificadores, es decir si las nuevas centralidades periféricas mejoran el acceso a la ciudad de los habitantes y en qué medida. Para ello, se basa en una encuesta de naturaleza cualitativa que analiza las prácticas socioespaciales en dos zonas de estudio: Suba-Pueblo y Patio Bonito-Tintal.

Palabras claves: centralidad urbana, periferias, Bogotá, prácticas socio espaciales, integración urbana, acceso a la ciudad

\section{Nouvelles centralités et accès à la ville dans les secteurs périphériques de Bogotá}

\section{Résumé}

Les transformations territoriales des secteurs périphériques de Bogotá ont favorisé l'émergence de lieux avec attributs de centralité. Par ailleurs, dans le Plan d'Aménagement Territorial de Bogotá (2000), les planificateurs conçoivent des centralités urbaines qui auraient pour vocation d'intégrer les espaces périphériques socialement défavorisés. Cet article examine donc si les transformations territoriales réelles coïncident avec le modèle conçu par les planificateurs, c'est-à-dire si les nouvelles centralités périphériques jouent un rôle dans I'intégration à la ville des espaces qu'elles polarisent. Pour ce faire,

* Estudiante de doctorado en Geografía. Laboratorio GECKO-Centre de recherche de géographie comparée des Suds et des Nords, Équipe d'accueil 375. Escuela de doctorado « Milieux, cultures et sociétés du passé et du présent ». Universidad Paris Ouest Nanterre La Défense, 200 avenue de la République-92001 Nanterre cedex. Actualmente investigadora del IFEA en Bogotá. E-mail: alicebeuf@yahoo.fr 
ce texte s'appuie sur une enquête de nature qualitative qui permet d'identifier les pratiques sociospatiales à l'œuvre dans deux zones d'étude : Suba-Pueblo et Patio Bonito-Tintal.

Mots clés : centralité urbaine, périphéries, Bogotá, pratiques socio-spatiales, intégration urbaine, accès à la ville

\title{
News centralities and Access to the city in peripheral areas of Bogota
}

\begin{abstract}
The territorial transformations in peripheral areas of Bogotá have fostered the emergence of places with attributes of centrality. On the other hand, in the Territorial Development Plan of Bogota (2000), planners design urban centralities which aimed to integrate socially disadvantaged peripheral areas. This article therefore examines whether the actual territorial changes coincide with the model conceived of by the urban planners, which is to say that the the new peripheral centralities have a role in integrating the spaces that they polarize. To do this, we rely on a qualitative survey that identifies the socio-spatial practices at work in two areas of study: Suba-Pueblo Bonito-Patio Tintal.
\end{abstract}

Keywords: urban centrality, peripheral areas, Bogota, sociospatial practices, urban integration, Access to the city

Las ciudades latinoamericanas conocen importantes procesos de transformación de sus áreas periféricas por la conjunción de dinámicas asociadas a la globalización (Sassen, 1991; Ascher, 1995; Veltz, 1996) y al crecimiento rápido que las caracterizan, aunque este haya disminuido con el fin de la transición urbana. Este contexto produjo un nuevo orden urbano caracterizado por la consolidación de la policentralidad. Las nuevas centralidades periféricas son formas urbanas inéditas definidas por la concentración de una oferta de servicios que polarizan un área de influencia más o menos extendida. Compiten directamente con el centro tradicional al atraer actividades y flujos que se reestructuran a escala metropolitana. La dependencia del centro principal está así puesta en tela de juicio. La policentralidad como nueva estructura urbana ha sido objeto de múltiples estudios a nivel latinoamericano (como mundial) que han investigado sus dimensiones funcionales, morfológicas, y relacionadas a la estructura de las movilidades (Garreau, 1991; De Mattos, 1999; Aguilar, 2002; Vignoli, 2008; Schelotto, 2009; etc.). Desde la antropología espacial se han investigado también las prácticas sociales de las centralidades especializadas emblemáticas que son los centros comerciales, concebidos como los nuevos espacios públicos de las ciudades contemporáneas (Capron, 1998; Cornejo Portugal \& Bellon Cardenas, 2001). Sin embargo, pocos estudios tratan de los usos populares de estos espacios del comercio global, que han surgido primero en los suburbios de clase media y alta pero que hoy en día se difunden en las periferias de clase media baja y baja, como por ejemplo en el caso de ciudad de México estudiado por Duhau \& Giglia (2007). Tampoco son analizadas las prácticas espaciales dentro del conjunto de 
los lugares que conforman las centralidades periféricas, más allá de los centros comerciales.

Para muchos autores, la policentralidad actual corresponde a:

«nuevos centros especializados o nodos que, interconectados por infraestructura y tecnologías de información y comunicación, funcionan prácticamente de manera independiente del resto de la ciudad» (Link, 2009: 19).

Las nuevas policentralidades no tendrían relaciones con sus entornos urbanos $y$, al contrario, constituirían manifestaciones de la fragmentación urbana (Borsdorf et al., 2002). Esta interpretación pone de relieve la tensión que existe entre la policentralidad real actual producida por la globalización y la policentralidad concebida dentro del marco de la planeación urbana inspirada por la teoría de los polos de desarrollo integral y por las experiencias de las «ciudades nuevas» del siglo XX. Por ejemplo, se profundiza en las grandes metrópolis el fenómeno de spatial mismatch, es decir la desarticulación entre los lugares de empleo y los espacios residenciales, desarticulación contra la cual tratan de luchar las políticas de movilidad a nivel metropolitano.

No obstante, unos gobiernos locales siguen refiriéndose a la idea de policentralidad para «equilibrar los territorios» a nivel urbano y metropolitano. Tal es el caso del Distrito de Bogotá que ha formulado un modelo de ciudad policéntrica dentro del marco del Plan de Ordenamiento Territorial (2000, revisado en 2003) (ALCADíA MAYOR DE BOGOTÁ, 2004). El POT propone consolidar y crear 22 centralidades urbanas, situados, en parte, dentro de los espacios periféricos. Las centralidades periféricas deben servir de palanca para la descentralización urbana y la difusión de actividades y equipamientos en lugares-referentes a nivel zonal. Se trata de disminuir la dependencia del centro metropolitano e integrar los espacios periféricos (Alba, 1998). Para ello, se utiliza la noción de «centralidades de integración» (Borja \& Castells, 1998: 371; Borja, 2003: 90) pensadas a distintas escalas. En el marco del POT, las centralidades «de escala nacional e internacional» son destinadas a proyectar la ciudad en el espacio económico internacional mientras que las centralidades «de escala urbana» deben acercar bienes, servicios y actividades a los espacios residenciales periféricos, densamente poblados y carentes de muchos elementos de urbanidad. Fortalecer el acceso a la ciudad es pensado como un elemento clave para lograr el objetivo de la equidad territorial, que orienta el POT junto con el objetivo de la competitividad urbana. Este artículo está motivado por la necesidad de evaluar esta ideología espacial y se concentra sobre el caso de las centralidades «de escala urbana».

Pretendemos examinar cuál es el impacto del surgimiento de lugares con atributos de centralidad sobre el acceso a la ciudad de los habitantes de las periferias bogotanas. Entre la figura de nuevas centralidades especializadas que funcionan en red a nivel metropolitano pero que no tienen mayor vínculo con sus entornos urbanos y la figura de centralidades de «integración» que difunden las oportunidades en el territorio, nos interesa indagar el significado social de los nuevos espacios de centralidad que surgen en las periferias bogotanas. 
En efecto, el acercamiento geográfico de los recursos urbanos no genera necesariamente mejoras efectivas en el acceso de los ciudadanos a la ciudad. Es bien conocido que distancia espacial y distancia social no coinciden (Chamboredon \& Lemaire, 1970). Incluso, las centralidades urbanas pueden fortalecer las divisiones socio espaciales. Para Lefèbvre (1974), la centralidad urbana puede ser un lugar integrador para los ciudadanos más pobres, que concrete su derecho a la ciudad, en la medida en que allí se dan una multiplicidad de usos y de interacciones sociales. Pero Lefèbvre insiste en que la centralidad en la ciudad capitalista muy a menudo no juega este papel sino que contribuye a diferenciar los espacios urbanos, lo que genera fenómenos de exclusión. Las centralidades tienen así un significado social que varía según los contextos urbanos. En Bogotá, son pocos los estudios sobre las transformaciones de las nuevas centralidades periféricas. Se puede citar el trabajo de maestría de Hurtado (2008) sobre la capacidad de los nuevos terminales de Transmilenio en generar integración urbana o elitización espacial y que esboza problématicas para seguir investigándose.

Este artículo no trata entonces del fenómeno de la policentralidad como tal, que supone un análisis a escala metropolitana (el Distrito de Bogotá y los municipios vecinos) y el manejo de bases de datos cuantitativos que no tenemos. Al contrario, pretende desarrollar una reflexión sobre la función integradora de nuevos lugares con atributos de centralidad. Para ello, se necesita profundizar las dimensiones cualitativas de las prácticas sociales de estos espacios, de sus usos por parte de las personas que los frecuentan: transeúntes, habitantes y trabajadores esencialmente. ¿Qué acceso a la ciudad brindan las centralidades periféricas? ¿En qué medida las políticas urbanas pueden apoyarse sobre estas dinámicas para fortalecer la equidad territorial?

Este trabajo se basa en dos estudios de caso: Suba-Pueblo (localidad de Suba) y Patio Bonito/Tintal (localidad de Kennedy). Ambos sectores presentan, además de una localización periférica y de muy altas densidades de población, transformaciones recientes debidas a inversiones, tanto públicas como privadas, que impulsan cambios de sus perfiles sociales y nuevas formas de interacción social (en particular entre grupos sociales medios-bajos y bajos). Este estudio se fundamenta en una encuesta aplicada a 29 transeúntes en Patio Bonito/Tintal y 30 transeúntes en Suba-Pueblo que realizamos en espacios públicos geográficamente seleccionados dentro de estos sectores y que corresponden a varios tipos de lugares con atributos de centralidad que detallamos más adelante. El objetivo era identificar las pautas de la movilidad cotidiana de los individuos para evaluar la importancia de las prácticas de las centralidades periféricas dentro de las prácticas de la ciudad en su conjunto y también destacar las representaciones y los usos de estos lugares. Profundizamos esta primera fase mediante veinte entrevistas a profundidad con habitantes y comerciantes de las áreas de influencia. Utilizamos también fuentes secundarias y datos cuantitativos para contextualizar los estudios de caso y corroborar algunas hipótesis. Finalmente, la observación directa de los usos y de las actividades en las zonas de estudio, tanto entre semana como los 
fines de semana, constituye una fuente de primera importancia para este trabajo1. Debido a la imposibilidad de alcanzar una representatividad en esta encuesta, se buscó dar énfasis a los aspectos cualitativos. Por esta razón, no daremos cifras de porcentaje en el análisis del cuestionario, sino que mencionaremos aspectos sobresalientes verificados en las entrevistas a profundidad y en las observaciones.

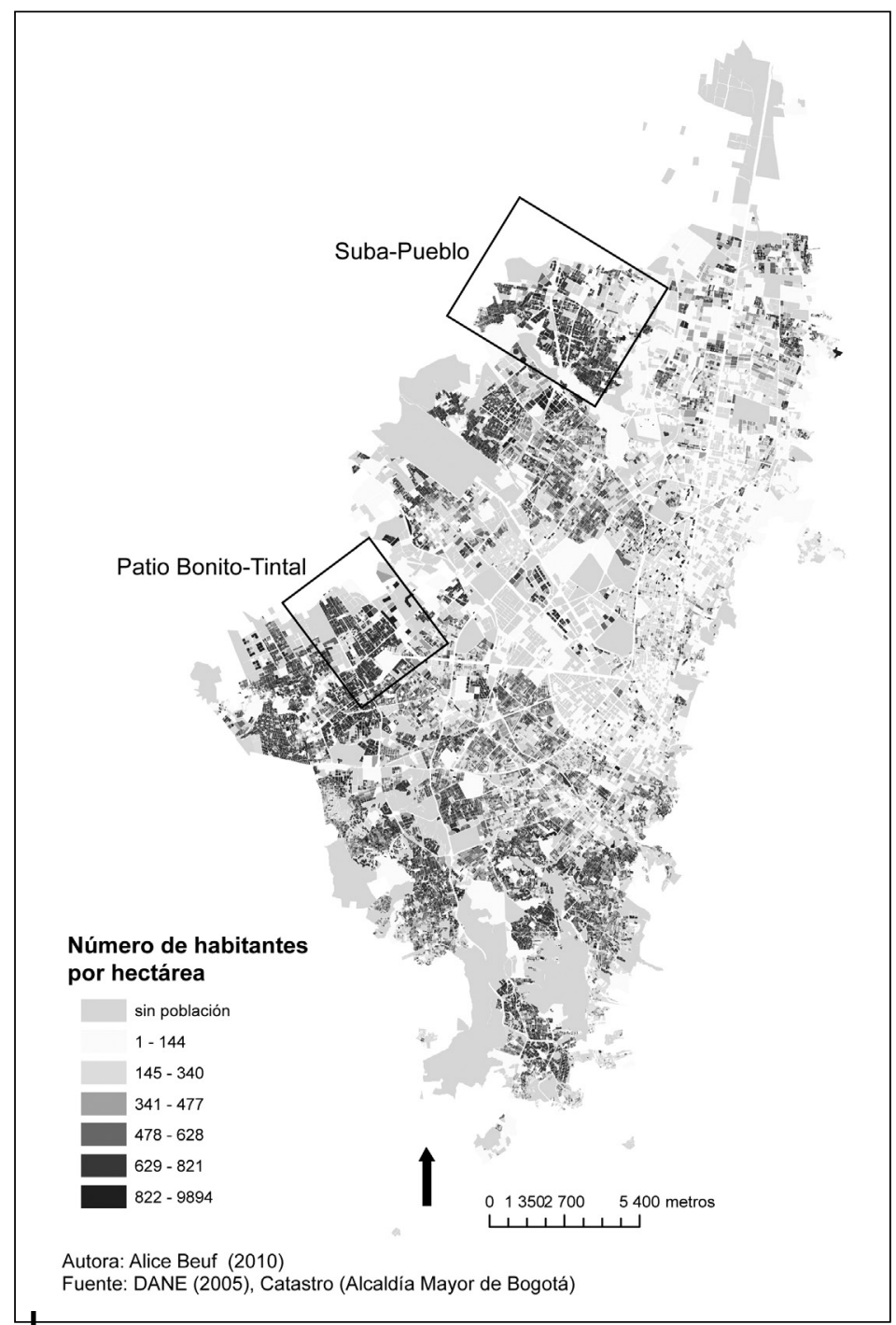

Figura 1 - Dos zonas de estudio densamente pobladas en Bogotá

1 Este trabajo de campo se realizó entre los meses de abril y agosto del 2009 gracias a una beca de ayuda a la investigación (BAR) otorgada por el IFEA. 


\section{SUBA-PUEBLO, PATIO BONITO/TINTAL: ESPACIOS PERIFÉRICOS CON ATRIBUTOS DE CENTRALIDAD}

Tras la exposición de los rasgos principales de estos espacios, explicamos por qué razones algunos de sus lugares presentan atributos de centralidad.

\section{1. Suba-Pueblo y Patio Bonito/Tintal: periferias en expansión}

Tanto Suba-Pueblo como, en menor medida, Patio Bonito/Tintal son sectores urbanos bien identificados por los bogotanos que los suelen frecuentar.

En el noroccidente de Bogotá, Suba-Pueblo presenta una cierta unidad espacial debido a su configuración topográfica: está aislado del resto de la ciudad por la colina de la Conejera y por el humedal Juan Amarillo. En la década de 1990, solo dos vías intermedias aseguraban la entrada y la salida hacia el resto de la ciudad. Los relatos de los habitantes nos recuerdan las pésimas condiciones de transporte de las cuales padecían para llegar a los lugares de empleo concentrados principalmente en el eje centro-norte de la ciudad. Además de estar relativamente aislado, Suba-Pueblo es un sector densamente poblado y con un fuerte crecimiento demográfico: entre 1993 y 2005, pasó de 281000 a 582000 habitantes2. Con una densidad promedia de $213 \mathrm{hab} / \mathrm{ha}$ en 2005, cuenta con unos de los sectores más densos de Bogotá, que pueden alcanzar localmente más de $500 \mathrm{hab} / \mathrm{km}^{2}$. Estas densidades son generadas por las altas tasas de hacinamiento en barrios horizontales como los del Rincón de Suba o de Lisboa. Para diferenciar la parte occidental de la localidad de Suba, la administración distrital empezó a utilizar el topónimo de Suba-Pueblo dando un nombre a esta unidad espacial, reconocida por los habitantes y anteriormente identificada como la comuna 92 de Suba. El núcleo urbano a partir del cual se ha extendido este sector periférico está conformado por el antiguo municipio de Suba, que fue anexado por Bogotá en 1954. Por esta configuración geográfica particular, por el tamaño de su población, y por su historia, Suba-Pueblo es todavía frecuentemente percibido como una «ciudad dentro de la ciudad» .

Por otro lado, Patio Bonito/Tintal corresponde a los barrios ubicados al occidente de la avenida Ciudad de Cali (construida a finales de los años 1990), entre los caños de los humedales del Burro y del Chucua de la Vaca. Es un sector igualmente identificado por los habitantes, a pesar de su división entre la parte sur que se ha desarrollado a partir del barrio de Patio Bonito desde los 1970

2 Censo de población del DANE (1993 y 2005). Cifras obtenidas por agrupación de sectores censales.

3 El modelo de las «ciudades dentro de la ciudad» ha sido introducido en Colombia en los años 1970 por el economista Lauchlín Currie que inspiró planes para controlar la expansión de las ciudades y concentrar los desarrollos en torno a nuevos centros en la metrópoli. Ver: Departamento Nacional de Planeación, 1974. 
(en este artículo llamamos «Patio Bonito» el conjunto de esos barrios), y la parte norte recientemente desarrollada sobre los terrenos de la hacienda del Tintal. Esta zona de expansión de la ciudad creció de manera vertiginosa, pasando de 95000 habitantes en 1993 a 338000 en 2005. En la parte de Patio Bonito, las densidades son aún más importantes que en Suba, con un máximo de 596 hab/ ha. La percepción de una «ciudad dentro de la ciudad» no existe en Patio Bonito, pero al sector se le otorga una identidad fuerte, tanto en lo positivo como en lo negativo. Los habitantes están orgullosos de su dinamismo demográfico y comercial que se observa en la «Principal» de Patio, la Calle 38 Sur, y reconocen la importancia del vínculo histórico de Patio Bonito con la Central de Abastos de Bogotá, en donde muchos trabajan o han trabajado. Pero también, Patio Bonito es famoso por las representaciones negativas y las discriminaciones de las cuales es objeto, en cuanto a su inseguridad, actual o pasada, real o imaginaria (al igual que ciertos sectores de Suba-Pueblo). Por su parte, el Tintal corresponde al sector colindante de Patio Bonito recientemente urbanizado de manera masiva bajo la modalidad de conjuntos cerrados para viviendas de interés social.

Estas periferias presentan hoy en día un dinamismo demográfico fuerte. Según los datos del Censo de población del 2005 (DANE), la población de ambos sectores es relativamente joven con relación al promedio de Bogotá. En Patio Bonito/ Tintal, los menores de 20 años (35 \% de la población bogotana) representan más del $40 \%$ de la población en la gran mayoría de los barrios (hasta 51 \% en un sector reciente de viviendas de interés social). En Suba-Pueblo, tasas similares de poblaciones jóvenes solo se encuentran en los barrios más periféricos (Bilbao, Lisboa, Santa Cecilia). Los demás sectores censales tienen entre 35 y $40 \%$ de menores de 20 años, y 34 \% en el sector del centro antiguo y de la colina de Suba. También, estas periferias presentan procesos de diversificación social. Poblaciones de clase media baja y de clase baja comparten estos espacios, en los cuales viven puntualmente poblaciones de clase media alta y en las márgenes, poblaciones de clase baja-baja. Según la estratificación socioeconómica colombiana4, es el estrato 2 que predomina, pero el estrato 3 está bien representado, sobre todo en Suba. Se observan también algunos sectores de estrato 4 (La Campiña en Suba, por ejemplo) y de estrato 1, en las partes más cercanas al río Bogotá (ver fig. 2). En términos de niveles educativos, encontramos importantes desigualdades internas que permiten profundizar esta aproximación a las pautas de segregación socio espacial. Según el censo de 2005, el porcentaje de acceso a la educación superior alcanza tasas superiores a los $25 \%$ en los alrededores del centro antiguo y de la colina de Suba así como en los nuevos barrios formales del Tintal, clasificados como de estrato 2, pero que tienen una población bien insertada socialmente. Al contrario, los barrios del sector amplio de Patio Bonito, así como la parte sur y

4 Colombia se ha dotado de una estratificación socioeconómica reglamentaria para subsidiar los servicios urbanos de los ciudadanos con bajos recursos. Así, se atribuye a cada manzana un estrato según la calidad física del entorno: del 1, para las manzanas que presentan condiciones más precarias al 6, para las que son más lujosas. 


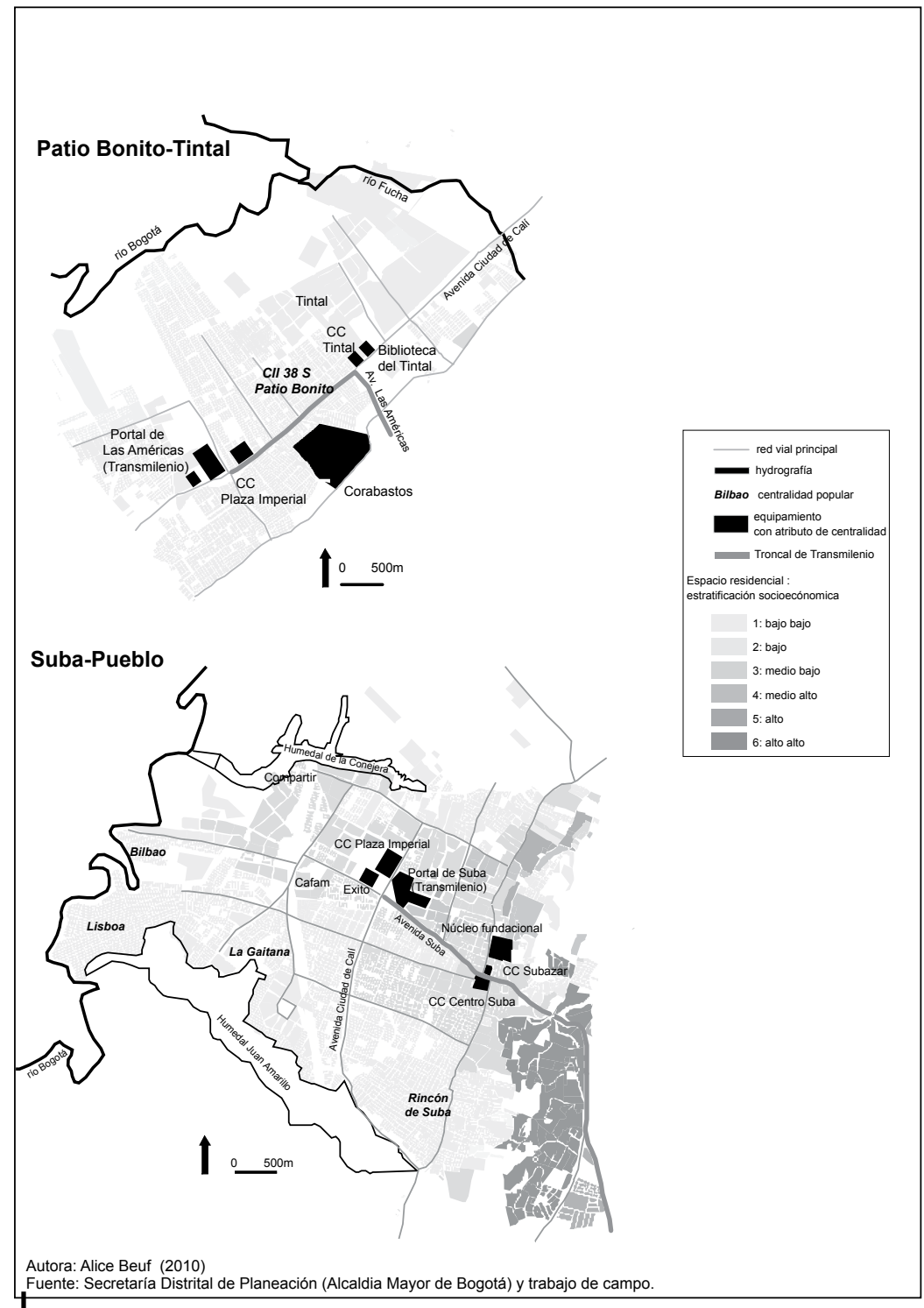

Figura 2 - Lugares con atributos de centralidad en las periferias bogotanas

occidental de Suba-Pueblo (Rincón de Suba, Lisboa, Gaitana) presentan tasas por debajo de los $10 \%$ de acceso a la educación superior.

En las periferias en expansión de Bogotá, las nuevas proximidades espaciales entre grupos sociales contribuyen a redefinir las modalidades del acceso a la ciudad y de la integración urbana como lo veremos más adelante. 


\section{2. Espacios periféricos producidos en varias etapas}

En Suba-Pueblo así como en Patio Bonito/Tintal, es frecuente encontrar conjuntos cerrados «formales», de vivienda de interés social o no, en los intersticios de los barrios autoconstruidos más o menos consolidados, lo que genera en ciertas partes una segregación socio espacial a escala de las manzanas. Esta configuración es el resultado de la complejidad de los procesos de producción de estos espacios.

En la mitad del siglo XX, las únicas urbanizaciones en estos sectores periféricos eran el pueblo fundacional de Suba, conformado por algunas manzanas construidas en torno al parque con la iglesia y la alcaldía, y unas haciendas en medio de las lagunas, los humedales, los cultivos y los pastos para el ganado. El crecimiento demográfico vertiginoso de Bogotá empujó a la urbanización de estos espacios periféricos. En Suba, las tierras pertenecientes originalmente a los indígenas muisca fueron vendidas para lotearlas de manera informal, al comienzo en el Rincón de Suba, separado del pueblo en esa época. La ola de urbanización informal llegó a su magnitud en los años 1960, en esta parte situada entre el humedal Juan Amarillo y el pueblo fundacional5. Por otro lado, en 1974, el terrateniente José Zamullo urbanizó de manera «pirata» los terrenos de su hacienda y vendió 1050 lotes de $6 \times 12$ metros sin servicios: es la primera etapa de Patio Bonito, rápidamente vendida y seguida por una segunda etapa de la misma amplitud. Los nuevos habitantes estaban atraídos por la proximidad a la Central de Abastos que ha constituido una importante fuente de empleo desde su apertura en 19726. Estos se organizaron luego, al igual que en los nuevos barrios de Suba, para luchar y conseguir poco a poco los servicios urbanos (agua, luz, alcantarillado) así como los equipamientos mínimos (vías, escuelas). Muchas veces, los habitantes tuvieron que pagar ellos mismos una parte de la instalación de las redes o de la construcción de las escuelas. A partir de los años 1980, mientras se seguían urbanizando nuevos sectores, se dieron las primeras legalizaciones de estos barrios de origen informal en vía de consolidación.

En 1994, las zonas más occidentales de Suba-Pueblo (Tibabuyes) y de Patio Bonito (Tintal-Central) así como la parte norte de este último sector (Tintal-norte) fueron definidas en el marco del Plan de Ordenamiento Físico para el sistema Hídrico y el Borde Occidental de Bogotá como grandes zonas de expansión de la ciudad con vocación a la vivienda de interés social7, normatividad que se mantuvo en los planes urbanos siguientes. En Suba, esta nueva dinámica se impulsó por iniciativa de grandes inversionistas privados luego de la construcción de la Avenida Suba, o «avenida nueva» en comparación con la antigua carretera.

5 Agradecimientos a José Miguel Barajas.

$645 \%$ de los primeros habitantes de Patio Bonito trabajaban en la Central de Abastos, según el relato de Manuel Díaz (26/07/2009), uno de los fundadores del barrio.

7 Pero, estas zonas se urbanizaron con predominancia de la categoría de «tope VIS» o sea viviendas cuyo precio alcanza los 135 salarios mínimos. Existen en Bogotá viviendas de interés social más baratas, a partir de 30 salarios mínimos en el caso de la vivienda de interés prioritario que están ubicadas en localizaciones poco accesibles y más al sur. 
Dos cajas de compensacións lanzaron los primeros grandes proyectos de vivienda de interés social en el occidente de Suba, en discontinuidad completa con la parte urbanizada hasta el momento: la primera Ciudadela Cafam y el proyecto «Suba-COMPARTIR» que contemplaba cinco etapas con 4200 apartamentos. Empezaron así a llegar a Suba nuevas poblaciones de un estrato social superior a los habitantes de los barrios autoconstruidos. Los bajos costos de la vivienda en comparación con otros proyectos de vivienda formal y una localización que, aunque periférica, queda en el norte de la ciudad9, fueron las principales motivaciones de estos nuevos subeños10. Simultáneamente, se habían construido los dos primeros centros comerciales, CentroSuba y Subazar, el uno frente al otro, en el cruce estratégico de la Avenida Suba y la carrera 91 (la segunda vía de entrada a Suba) y a proximidad de la plaza fundacional.

Por su parte, la zona del Tintal es conocida por haber sido una de las primeras experiencias de concertación exitosa entre los propietarios de la tierra11, la Administración Distrital y las empresas de servicio (acueducto) para urbanizar de manera formal, con viviendas de interés social, los terrenos periféricos. En el marco de este acuerdo de 1994, se preveía que la zona, con sus extensiones al norte y al sur, pudiera albergar 350000 personas12. Estas previsiones no se cumplieron completamente, pero se ha observado un fuerte crecimiento demográfico en el sector de Tintal13 que se mantiene hasta hoy gracias a la apertura de nuevos conjuntos residenciales a un ritmo elevado. Igual que en Suba, el desarrollo del Tintal ha beneficiado de la construcción de una vía arteria, la Avenida Ciudad de Calí, que ha llegado al sector a finales de los años 1990.

Estas periferias en expansión experimentaron un cambio importante a comienzos de los años 2000 con la llegada del sistema de transporte masivo en sitio propio por buses articulados Transmilenio, que no solamente mejoró la accesibilidad sino que también transformó los espacios públicos, generando un nuevo orden urbano. Estos cambios contribuyeron a revertir las representaciones negativas de estos territorios. Otro símbolo del nuevo rumbo de las periferias fue la inauguración en 2001 de la Biblioteca del Tintal, una de las tres bibliotecas mayores de Bogotá.

8 Las cajas de compensación en Colombia son instituciones privadas de seguridad social que prestan servicios a sus afiliados, entre otros: subsidios familiares, servicios de recreación y cultura, subsidios de vivienda en el marco de proyecto de viviendas gestionados por las mismas cajas.

9 El norte es la parte más prestigiosa a escala metropolitana. Pero se trata de los espacios al oriente de la colina de Suba. En el norte, en la parte rural, quedan también los buenos colegios privados. Acercarse al colegio de los hijos es un factor importante de la movilidad residencial de las familias en Bogotá.

10 Entrevista con Germán Tellez, consultor, encargado del estudio de mercado para la primera Ciudadela Cafam de Suba (30/07/2009).

11 Los Tintales Norte y Sur constaban de 471 hectáreas de terreno y poseían 24 propietarios; en el Tintal Central, 7 propietarios se compartían 740 ha.

12 Ver artículo «Tintal, Polo De Desarrollo Urbano»: El Tiempo, 10 de septiembre de 1994.

13 Otro factor de crecimiento, pero menos importante, es la densificación de los barrios autoconstruidos por la verticalización y el hacinamiento. 
Las inversiones públicas en infraestructuras fueron seguidas en un segundo tiempo por inversiones de naturaleza social a partir de 2004: construcción de colegios distritales, hospitales14, parques...

El crecimiento de los espacios residenciales y las mejoras en término de infraestructuras y movilidad generaron importantes expectativas de desarrollo en Suba-Pueblo y Patio Bonito/Tintal, que se concretaron por medio de inversiones privadas. Apareció una nueva generación de centros comerciales con los mismos estándares 15 que los de los barrios más pudientes del norte. Empresas multinacionales (Carrefour, Falabella, Sodimac...) constituyen los almacenes anclas de los centros comerciales Plaza Imperial en Suba, Tintal o Plaza Milenio en Kennedy. Estos nuevos polos de consumo masivo están rodeados, sobre todo en Suba, por una serie de supermercados especializados. Los nuevos desarrollos comerciales valorizaron los sectores de Suba-Pueblo y Patio Bonito/Tintal, en particular en sus partes que se volvieron centrales. La oferta residencial ya no es exclusivamente para vivienda de interés social. Incluso, se observa hoy en día la construcción de torres de 15 pisos de estrato 4 en las inmediaciones del centro comercial Plaza Imperial en Suba y al frente del centro comercial Tintal.

Simultáneamente, durante los últimos 10 años, se desarrollaron de manera prodigiosa una multitud de actividades económicas en los barrios de origen informal, hoy legalizados. Diferentes tipos de actores económicos entraron a operar en estos espacios que conocen actualmente procesos potentes de diferenciación interna.

Los territorios periféricos de Suba-Pueblo y Patio Bonito/Tintal, en crecimiento rápido, presentan una complejidad espacial interna importante debido a la pluralidad de sus modos de producción. En este contexto, surgieron distintos tipos de lugares con atributos de centralidad.

\section{3. Distintos tipos de lugares con atributos de centralidad}

Según su antigüedad, sus funciones, su dinámica, los actores económicos involucrados y la clientela a la que se destinan, se pueden identificar categorías de lugares que «hacen centro» a varias escalas en las periferias bogotanas.

\section{3. 1. Los centros fundacionales de los municipios anexados en 1954}

En Suba, que era municipio independiente, el parque constituye un hito en el paisaje urbano. Todavía tiene un significado particular para la localidad en su conjunto debido a una concentración institucional en sus alrededores (alcaldía

14 El Hospital de Suba abrió en 2006 y la apertura del Hospital del Tintal está prevista para 2011.

15 Según las palabras de un representante de las élites bogotanas, Germán Tellez (citado anteriormente), estos son: «mismos almacenes, misma calidad de los acabados, parqueaderos iguales de repletos en carros»». 
menor de Suba, servicios locales de la Secretaría de Integración Social, iglesia, notaría, estación de bomberos y biblioteca) y a una dimensión cultural inédita en las periferias (organización de eventos culturales, presencia de edificios patrimoniales). En Kennedy, que no era un municipio, la centralidad institucional no tiene significado simbólico ni cultural y queda más cerca al centro que la zona de estudio. A pesar de la existencia de relaciones importantes de los habitantes de Patio Bonito-Tintal con los sectores centrales (institucionales y comerciales) de la localidad Kennedy, hemos decidido limitar el estudio al sector más periférico de Patio Bonito-Tintal.

\section{3. 2. Los centros comerciales de primera generación y los sectores comerciales aledaños}

Se trata de los primeros centros comerciales que fueron construidos a comienzos de los años 1990 en Suba y que agregaron en torno a ellos distintas actividades de carácter popular. Los centros comerciales como tales son de dimensiones pequeñas (menos de 20 000m² de área comercial) en comparación con los de las zonas pudientes; no albergan almacenes lujosos sino locales destinados a las clases populares, aunque hayan algunas cadenas de cierto prestigio. Las zonas comerciales que los rodean contribuyen a una intensa frecuentación. Por ejemplo, el puente peatonal entre CentroSuba y Subazar, que también es el puente de acceso a la estación de Transmilenio «Carrera 91», es uno de los más transitados de Bogotá. Estos sectores comerciales se consolidaron en relación con el sistema de transporte tradicional, a proximidad de los semáforos y sobre las líneas de buses que tienen un alto nivel de isotropía. Posteriormente, la llegada del sistema de transporte masivo Transmilenio, y la reordenación de los espacios públicos que la acompañó, redistribuyó las rentas de accesibilidad: ciertos comercios se beneficiaron de los cambios, mientras que otros bajaron su actividad, incluso algunos pequeños talleres o almacenes tuvieron que cerrar.

\section{3. 3. Las centralidades populares}

Llamamos «centralidades populares» las concentraciones de servicios y comercios pequeños y medianos (incluyendo supermercados) que polarizan un conjunto de barrios y que son identificadas como tales por los habitantes. Tienen un nombre y son asociadas a referentes urbanos reconocidos: terminal de línea de buses, iglesia. En su mayoría, se consolidaron a partir de una plaza de mercado. Pero algunas surgieron a partir de la concentración de actividades no mercantiles (conjunto de asociaciones, ONG, equipamientos públicos como en el caso de la Gaitana en Suba). Su grado de consolidación depende de su antigüedad y de su localización estratégica sobre las vías intermedias internas a las periferias. Las centralidades más importantes (alrededores de la Calle 38 Sur conocida como la «Principal» de Patio Bonito, Rincón de Suba) presentan un grado elevado de diversificación y de especialización: clínicas odontológicas y de salud privadas, joyerías, supermercados, almacenes de cadena, institutos de formación profesional, salas de eventos... Por 
lo tanto, si bien están ubicadas en barrios de origen informal y si bien una gran parte de las unidades económicas que allí se encuentran son informales, estas centralidades de escala zonal conocen un dinamismo económico importante.

\section{3. 4. Los nuevos sectores centrales}

Estos espacios muy recientemente creados (cinco años aproximadamente) surgieron a raíz de la puesta en servicio del sistema de transporte masivo Transmilenio que produjo nuevas condiciones de accesibilidad y paisajes urbanos percibidos como más «ordenados» a lo largo de las arterias en las periferias. Estas características dieron las condiciones para que nuevos inversionistas se interesaran en los sectores periféricos con expectativas de desarrollo. Encontramos entonces, como ya lo mencionamos, centros comerciales de última generación y diversas tiendas de grandes dimensiones pero también equipamientos públicos de escala urbana o metropolitana: portales o terminales de Transmilenio que conforman los nuevos nodos de movilidad de Bogotá (portal de Suba y portal de las Américas en Patio Bonito-Tintal), grandes centros de servicios administrativos llamados Supercades (Supercade Suba y Supercade de las Américas al frente de los respectivos portales), la biblioteca del Tintal.

\section{3. 5. Una centralidad especializada: Corabastos}

La central de Abastos de Bogota, definida en el POT como «centralidad de integración» de Corabastos, colindante con Patio Bonito, tiene que mencionarse aparte. Actualmente, es el primer centro de acopio y comercialización, mayorista y minorista, de la producción agrícola y agroindustrial de Colombia: diariamente ingresan 200000 personas, 12500 camiones, 6500 comerciantes y 11000 toneladas de alimentos que vienen de todas las regiones del país16. A pesar de su vínculo histórico con el sector de Patio Bonito, hoy en día la Central de Abastos, encerrada por un muro elevado y que se especializa cada vez más en el comercio mayorista, tiene una dinámica propia y pocas interacciones con su entorno. Se podría decir que si Corabastos generó la demanda de vivienda que impulsó el desarrollo de Patio Bonito en los años 1970, ahora este conjunto de barrios alberga poblaciones tan numerosas y tan diversas en sus orígenes y sus relaciones con la ciudad que solo una pequeña proporción de sus habitantes depende de la Central de Abastos.

Los sectores de Patio Bonito/Tintal y Suba-Pueblo son entonces espacios complejos conformados por una diversidad de lugares con atributos de centralidad. La transformación más importante de estos últimos años es el surgimiento de los nuevos sectores centrales, por haber atraído a las periferias equipamientos de escala metropolitana. Sin embargo, esto no significa que las centralidades 
periféricas se reducen a estos únicos lugares. En efecto, los demás lugares con atributos de centralidad, y en particular las centralidades populares, también se han fortalecido. El estudio de las prácticas espaciales debe aproximar la manera en que los ciudadanos se relacionan con cada uno de estos lugares. ¿Existen lugares exclusivos para ciertas categorías de población? O ilos habitantes saben apropiarse de cada lugar según las oportunidades que éstos les ofrecen? ¿Tejen entre sí relaciones de complementariedad los distintos tipos de lugares con atributos de centralidad?

\section{CENTRALIDADES PERIFÉRICAS Y ACCESO AL EMPLEO}

El acceso a la ciudad está determinado en primer lugar por el acceso al trabajo definido como un derecho fundamental en la Constitución colombiana de 1991 (art. 25). Según la Cámara de Comercio de Bogotá y Fedesarrollo, de los 3,5 millones de personas ocupadas en la capital colombiana, 1,8 millones (53 \%) trabajaban en condiciones de informalidad en 2008. La estructura espacial del empleo, aproximada gracias a la Encuesta de Movilidad (DANE-STT, 2005) muestra que la principal aglomeración de empleo de la ciudad está localizada en el cono centro-norte, lo que genera importantes flujos de movilidad desde las periferias hacia este centro expandido (Gutiérrez, 2008: 28). Sin embargo, se notan algunos polos de segundo nivel en las periferias que presentan altos volúmenes de empleo. A nivel de las Unidades de Planeación Zonal17, destacan Bosa Central, Fontibón y el Rincón de Suba, que pertenece a la zona de estudio de Suba-Pueblo. Patio Bonito constituye también una concentración importante, y aparece como de segundo orden en estos estudios del empleo en Bogotá, en parte sesgados por las delimitaciones de las UPZ.

Ambas zonas de estudio están caracterizadas por una alta predominancia del sector de los servicios (87,5 \% en el Rincón en 2008 según los cálculos de Gutiérrez a partir de la encuesta de Movilidad y de la base catastral) y una alta proporción de micro establecimientos, lo que indica una tasa alta de informalidad empresarial y laboral (97 \% en el Rincón y Suba centro en 2002 según el registro comercial de la Cámara de Comercio), sobre todo en el sector del comercio. En este contexto de fuerte presencia de la informalidad económica, ¿en qué medida la llegada de actividades de escala metropolitanas influye sobre el acceso al empleo? Una parte de la encuesta consistió en evaluar este punto en particular y reveló situaciones complejas.

17 Las Unidades de Planeación Zonal son delimitaciones territoriales de escala superior a los barrios e inferior a las localidades, que sirven para la planeación urbana pero también para los estudios estadísticos. Suba-pueblo está conformado por 3 grandes UPZ: Rincón, Suba central y Tibabuyes. Patio Bonito/Tintal corresponde a las UPZ de Patio Bonito, Corabastos, Calandaima, Tintal Norte, y una parte de Castilla. 


\section{1. El débil impacto del empleo en los nuevos sectores centrales}

El primer aspecto sobresaliente de la encuesta es que la implantación de nuevas actividades formales, ligadas a inversiones privadas exteriores a la zona, no tiene un impacto importante sobre el empleo de las poblaciones circunvecinas. Ofrecen empleos de ejecución en el sector de los servicios. Pero las entrevistas realizadas dentro de los centros comerciales y las grandes tiendas muestran que las empresas ubicadas allí funcionan bajo esquemas organizativos que no dan prioridad al empleo de personas de la zona. Las empresas prefieren traer sus propios profesionales, y muchas veces los hacen rotar de sitio de trabajo en toda la ciudad. Nuestras entrevistas dejan suponer una estabilidad laboral muy baja. Este modelo de trabajo flexible se aplica para cualquier tipo de empresa que opera en estos sitios: bancos, empresas comerciales, de seguridad, de aseo, etc. Para los bogotanos que aspiran a este tipo de empleos en el sector privado formal, ya no es posible esperar trabajar cerca de su lugar de residencia por una larga duración. Este modelo empresarial contradice los proyectos de los planificadores urbanos que proponen ordenar el territorio, equilibrarlo y reducir las necesidades de desplazamientos, como se expresa por ejemplo en el POT. Entrevistamos sin embargo a algunas personas que reconocen haber encontrado trabajo en los nuevos espacios de su sector de residencia como, por ejemplo, un conductor de buses Transmilenio, que trabaja en el Portal de Suba18. En este caso, que es minoritario, los trabajadores pueden buscar una vivienda cerca de su lugar de trabajo.

Sin embargo, la implantación de los nuevos centros comerciales y grandes tiendas multinacionales beneficia a algunos de los comerciantes de las zonas aledañas, debido a la existencia de relaciones de complementariedad que nos fueron comentadas en el marco de entrevistas a comerciantes. Las tiendas, los pequeños supermercados de barrio, las fotocopiadoras, las discotecas sacan provecho de los flujos de personas generados por los centros comerciales y los hipermercados. Los pequeños comercios se están multiplicando en las inmediaciones de los nuevos sectores centrales. Incluso, a veces, se surten en la gran distribución cercana para rendir servicio a sus clientes, como por ejemplo completar los mercados llevados a domicilios. Grandes tiendas y comercios de proximidad tienen mercados muy distintos y no se hacen tanta competencia, a pesar de la existencia de casos de tiendas que fueron cerradas.

Los vendedores ambulantes reconocen también que las nuevas formas de comercio tienen un impacto positivo sobre su empleo. Sistemáticamente comentaron tener más oportunidades de trabajo ahora: «Hay más gente, la venta es mejor». Así se explica el incremento del comercio informal en los espacios públicos amplios de los nuevos sectores centrales, construidos simultáneamente al Transmilenio. Los fines de semana, los andenes de la Avenida Ciudad de Calí (en Suba y en Patio Bonito-

18 Entrevista con Isabel Cristina Rojas Marulanda, directora de la expansión, Carrefour Colombia, 24/02/2009. 
Tintal) conforman nuevos paseos urbanos. Están llenos de vendedores ambulantes y de mercancías que se venden a las familias que se fueron caminando a «vitrinear» y a «pasar el rato» sin comprar en los centros comerciales: estas familias compran más bien a la salida a los vendedores ambulantes o en las centralidades populares. No obstante, hay comerciantes que padecen fuertemente de la llegada del comercio de mayor escala. Es el caso de los antiguos comerciantes especializados, como las ferreterías que entran en competencia directa con las tiendas especializadas de la multinacional Sodimac «HomeCenter», presente en el centro comercial Plaza Imperial de Suba. Varios comerciantes del sector comercial antiguo de Suba se ven así fuertemente afectados. Además, su situación había ya padecido de las obras de Transmilenio que, al construir una troncal en la Avenida de Suba, habían desviado gran parte de las líneas de transporte público que les traían sus clientes. Varios comercios, relacionados al antiguo sistema de movilidad, tuvieron que cerrar y buscar formas de reconversión sin ningún apoyo por parte de las autoridades. El centro comercial antiguo de SubaCentro se encuentra también en una situación económica muy frágil por efecto de la competencia del nuevo sector central. Según su gerente que entrevistamos, presenta una tasa de desocupación de los locales de $10 \%$ debido a desplazamientos hacia el nuevo centro comercial de Plaza Imperial.

\section{2. Las alternativas de empleo que ofrecen las centralidades periféricas: la reproducción del modelo desigual}

Los impactos sobre el empleo de los «nuevos sectores centrales» son así bastante mitigados. Pocas personas de las zonas de influencia sacan provecho de la llegada de los nuevos desarrollos en el sentido de encontrar o consolidar una actividad laboral digna. No obstante, si consideramos las centralidades periféricas como un conjunto de lugar más amplio que los solos «nuevos sectores centrales», encontramos que juegan un papel importante sobre el empleo, bajo otras modalidades.

Primero, se observa una proliferación de actividades económicas y de comercios (formales, semi-formales e informales) en las centralidades populares, en los barrios de origen informal y a proximidad de los nuevos conjuntos residenciales. Las actividades presentes en estos lugares, por su cantidad, ofrecen muchas oportunidades de trabajo a los habitantes de las periferias. Sin embargo, son actividades de niveles económicos muy diversificados. En el caso de las cadenas (almacenes de zapatos, supermercados, clínicas odontológicas) y de los negocios pertenecientes a inversionistas que intervienen en toda la ciudad (talleres de confección, almacenes mayoristas o minoristas), las entrevistas revelaron que una proporción significativa de los empleados vienen de otras partes de la ciudad. Sin que hayamos podido investigar suficientemente el asunto, suponemos la existencia de redes profesionales que se tejen entre las centralidades populares de todo Bogotá y posiblemente en el país. Otro segmento importante de las actividades que se encuentran en este tipo de lugar está conformado por microempresas 
familiares, que forman la base de la economía informal (Lautier, 2004). En este caso, se trata principalmente de personas que montaron un pequeño negocio en su propia casa para generar ingresos que permitan sobrevivir. Los entrevistados comentaron que la poca capacidad de acumulación está compensada en parte por las ventajas en términos de calidad de vida que ofrece el trabajo a domicilio en comparación con un trabajo de empleado en el sector formal, bajo el esquema de la flexibilidad laboral. En esta perspectiva, la ubicación precisa de la vivienda en el barrio se vuelve un recurso económico. Un entrevistado se quejó por ejemplo de que su casa esté ubicada en una parte poca transitada del barrio Bilbao, alejada de la centralidad popular que allí se encuentra. Por esta razón, no puede montar un negocio a domicilio como quisiera y debe desplazarse hacia el portal Norte de Transmilenio, en donde trabaja como ambulante. Son así los sectores de origen informal, legalizados y que presentan una proliferación de actividades económicas, los que ofrecen de manera consecuente oportunidades laborales para los habitantes de las periferias.

Las estadísticas del empleo en estos sectores, con altos niveles de empleo a «cuenta propia» y de empleo de baja calificación (más de 30000 y de 80000 en el Rincón de Suba) corroboran estos resultados 19. Son los empleos informales, que se refieren a realidades económicas muy variadas, los que explican también las altas tasas de movilidad intrazona por motivo de trabajo encontradas en la Encuesta de Movilidad (DANE-STT, 2005) en el sector del Rincón de Suba (28 \%), y en menor medida en Patio Bonito (22 \%). La tasa promedio en Bogotá es de $11 \%$ de viajes intra-zona.

Finalmente, las centralidades periféricas tienen un impacto indirecto pero fuerte sobre el acceso al empleo al ofrecer nuevas condiciones de movilidad, mucho más eficientes gracias a la puesta en servicio del sistema de transporte masivo Transmilenio. Los terminales o «portales» de Transmilenio de Suba y de Américas conforman los nuevos nodos de transporte de las dos zonas de estudio. Uno de los aspectos más sobresaliente de las entrevistas corresponde a las mejoras percibidas efectivamente en los tiempos de viaje desde las periferias hacia el centro expandido (eje de desarrollo centro-norte). Se benefician así principalmente del Transmilenio los estudiantes de las universidades, los empleados del sector formal y los vendedores informales que se surten en el centro. Sin embargo, a partir de nuestras entrevistas, hemos podido destacar que las personas que viven y trabajan en los sectores periféricos usan poco el sistema Transmilenio. Se desplazan más en transporte público tradicional o en cicla. Patio Bonito es así la zona de la ciudad con más tráfico de ciclas, privados o colectivos (desarrollo importante de los bicitaxis en este sector). Los buses alimentadores de Transmilenio (gratuitos) no alcanzan a organizar las movilidades de proximidad. Ofrecen solamente un servicio para desplazarse puntualmente dentro de las periferias o para llegar a los portales, de donde salen las líneas troncales.

${ }^{19}$ Secretaría Distrital de Planeacion (2009), Bogotá, ciudad de estadísticas, Boletín N. ${ }^{0}$ 12: 30, Análisis espacial del mercado laboral en Bogotá. 
Al privilegiar los trayectos centro/periferias y no las intensas movilidades de proximidad en las periferias, la nueva organización del transporte, impulsada por el Transmilenio, tiende a reproducir el esquema de dependencia de las periferias hacia el centro expandido, el principal lugar de empleo de la ciudad.

Tanto en Suba-Pueblo como en Patio Bonito/Tintal, la consolidación de nuevas centralidades mejora el acceso de los habitantes al empleo formal por su conexión al resto de la metrópoli vía los nodos de transporte masivo, y no tanto por los empleos que ofrecen en las nuevas actividades. Sin embargo, la proliferación del empleo informal que acompaña estas dinámicas, por la complementariedad que existe entre las actividades formales e informales y por las mismas dinámicas de las centralidades populares, ofrece oportunidades laborales para una gran parte de los habitantes de las periferias, bajo condiciones laborales precarias.

\section{EL ACCESO DIFERENCIADO A LOS BIENES Y SERVICIOS}

Las transformaciones territoriales, que llevan a la consolidación de lugares con atributos de centralidad en las periferias, cambian igualmente las modalidades de acceso a los recursos urbanos, los bienes y servicios como los equipamientos que permiten la satisfacción de las necesidades de los individuos y contribuyen al ejercicio de sus derechos sociales y culturales.

\section{1. Acceder al consumo como primera forma de integración urbana}

En la consolidación de las centralidades periféricas está en juego el acceso al consumo de los pobres urbanos: poblaciones con un débil poder adquisitivo a nivel individual pero que logran una «masa crítica» consecuente gracias a las altas densidades de los barrios periféricos.

Nuestra encuesta reveló que las transformaciones recientes de las periferias son percibidas globalmente de manera muy positiva por los ciudadanos. A pesar de algunas inquietudes (inseguridad, incremento de los costos de la vida), los habitantes y transeúntes de las periferias valoran el «progreso», el «crecimiento de la ciudad y su desarrollo». Dentro de este imaginario de la modernidad, tiene una prima importancia el incremento del comercio bajo todas sus formas. Las personas entrevistadas en su gran mayoría insisten en la existencia de más variedad de la oferta comercial. Así, más que el acceso a ciertos bienes y servicios, los entrevistados subrayan el acceso al consumo. Este es un tema cuyas dimensiones simbólicas e identitarias son bien conocidas (Capron, 1998).

Este acceso al consumo desde las periferias está relacionado con la disminución de la dependencia al centro en cuanto al comercio banal y parcialmente en cuanto al comercio específico, como lo demostró la Encuesta de Movilidad de 2005 en comparación con la encuesta anterior JICA-CHODAI CO. Ltd. (1996). 
Para los habitantes de las periferias que entrevistamos, el centro sigue siendo un espacio comercial únicamente para ciertas categorías de productos (trajes a la medida, materiales para actividades creativas por ejemplo). Además, la mayoría de las personas que siguen yendo al centro para comprar, suelen frecuentarlo desde hace mucho tiempo.

«Ahora se encuentra de todo por acá, uno no gasta en transporte ni en tiempo para conseguir las cosas».

Sin lugar a dudas, ésta constituye una de las percepciones más compartidas y más valoradas por los habitantes de las periferias, principalmente de clase popular pero igualmente de clase media. Para estas categorías de personas, la movilidad es un problema porque su tasa de motorización es baja y porque las periferias se ven más afectadas por la congestión. «Conseguir las cosas» es la principal preocupación de las personas de más bajos recursos. Además, es un criterio de valoración de la ciudad, que determina para estas poblaciones el apego que le reconocen a un sector o a un barrio. Para esta categoría de personas, el espacio urbano es un medio donde encontrar los elementos necesarios a la vida. La relación a la ciudad es muy funcional; el sentimiento de pertenencia en términos identitarios y afectivos, a la ciudad en su conjunto o a unos barrios en particular, es débil. Lo que se valora, son más bien las oportunidades que la ciudad ofrece. Y la primera oportunidad de todas es la posibilidad de conseguir fácilmente «comida buena y ropa bonita». Al contrario, para las personas recién llegadas a las periferias que tienen los códigos culturales de las clases medias y altas colombianas, el comercio es percibido como degradante para su entorno. Daña los sectores residenciales al traer ruido, suciedad y desorden. Por eso, los centros comerciales, que son una forma de comercio percibido como arreglado y muy delimitado en su entorno, tienen mucho éxito para estas poblaciones, pero también para una parte de las poblaciones arraigadas en los sectores populares quienes tienen una fascinación para la novedad y el consumo.

Más allá de la satisfacción de las necesidades básicas (el acceso a los alimentos y al vestido, a pesar de la barrera monetaria que siempre es la más discriminante), este proceso de incremento y diversificación de la oferta comercial es una manifestación del pasaje de las periferias populares a la era del consumo. A distintos niveles según sus capacidades económicas, los individuos buscan consumir, adecuándose a la tendencia mundial. «Ya no se compra lo estrictamente necesario en la tienda, se puede antojar», nos comentó una madre de familia que vive en el nuevo barrio para clases medias del Pinar de Suba y que frecuenta de manera asidua el centro comercial cercano de Plaza Imperial. Las clases medias, que han Ilegado a vivir en los nuevos conjuntos residenciales formales o que han consolidado su posición económica dentro de los barrios autoconstruidos, conforman los principales consumidores de estos sectores. Pero también, las poblaciones de más bajos recursos están involucradas en esta dinámica, tal vez de manera más débil a nivel individual, pero de manera fuerte a nivel colectivo.

Es un elemento que analizaron muy bien los inversionistas de la gran distribución, por ejemplo la firma Carrefour que desarrolló una estrategia específica para entrar 
a los sectores populares de las periferias bogotanas, de modo similar a lo que describen Duhau \& Giglia (2007: 88) para la ciudad de México. Las directivas de esta multinacional tenían como punto de partida el hecho de que «las personas de bajos recursos también necesitan comer, vestirse» y que «a veces sacrifican muchas cosas para regalarse un televisor de pantalla plana». Analizaron que estos comportamientos, por la masa demográfica, podían asegurarles la rentabilidad de sus tiendas20. Así, Carrefour abrió una tienda de dimensiones y de un diseño inéditos en el pequeño centro comercial Plaza Milenio del barrio Tintalito en Patio Bonito: un sector en el cual los habitantes presentan apenas solvencia económica. Se introducen de esta manera nuevas pautas de consumo (pago por tarjeta de crédito en lugar de afianzar, mercado al mes y no al día) que vienen poco a poco a suplantar las prácticas de compras en las tiendas barriales.

A pesar de las percepciones positivas sobre la variedad de la oferta comercial, una parte importante de las personas entrevistadas denuncian el aumento de los costos que traen consigo las transformaciones del comercio. Sin embargo, la exclusión económica, percibida claramente por los ciudadanos de bajos recursos, no significa el rechazo de las nuevas formas comerciales. Observamos así una paradoja importante que consiste en valorar lo visto aún si no se le puede apropiar. Los habitantes de bajos recursos casi no compran en los grandes centros comerciales y tiendas nuevas, pero sí los frecuentan y los usan mucho. Ver la variedad de cosas, ver las nuevas arquitecturas, usar las instalaciones comerciales, son elementos muy apreciados. Los niños pueden pasar toda una tarde jugando con las escaleras mecánicas del centro comercial de Plaza Milenio: son las únicas de Patio Bonito.

El motivo económico, asociado a motivos culturales y personales (arraigo a un lugar particular debido a su historia de vida) explica la complejidad de las estrategias espaciales de compras de la mayoría de las personas entrevistadas. Los arbitrajes se realizan dependiendo de la naturaleza de lo que se quiere comprar. En una entrevista, una antigua residente del sector de Patio Bonito, ama de casa, explica que va de compras en el supermercado del barrio en la Calle 38 Sur (Corratienda, siempre presente en las centralidades populares) pero que para el champú se desplaza hasta el Carrefour de Tintalito, donde de paso, si tiene dinero, puede realizar otras compras no previstas. A partir de las preguntas del formulario sobre lugares de compras (mercado, ropa, compras específicas) y de las entrevistas a profundidad, aparece que el mercado de plaza y las tiendas siguen teniendo éxito para los clientes que realizan un mercado al mes en los hipermercados, pero que necesitan complementos al día. Para la ropa, las clases medias acuden más al comercio de marca, que propone precios más caros, sin que eso impida a una buena proporción de habitantes de esta categoría frecuentar locales comerciales de productores o pequeños empresarios informales o semi informales. Igualmente, las poblaciones más pobres compran ocasionalmente productos en las tiendas de marca de los centros comerciales y son muy atentos a los días de promoción.

20 Pero también se pensaba en las expectativas de nuevos desarrollos residenciales y de mejoramiento de los barrios informales que harían «madurar» el mercado. Entrevista con Isabel Cristina Rojas Marulanda, directora de la expansión, Carrefour Colombia, 24/02/2009. 
Finalmente, son muy pocas las personas entrevistadas que realizan el conjunto de sus compras de mercado o de ropa en una sola categoría de lugar: se trata sobre todo de los más pobres que compran todo en la tienda y los comercios del barrio o de las franjas más altas de las clases medias recién llegadas, que frecuentan únicamente el centro comercial cercano, por cuestiones de seguridad o solamente porque no conocen el sector. Estos resultados corroboran también la diversidad de las prácticas de compras encontradas en Ciudad de México (Duhau \& Giglia, 2007: 81).

En este contexto, observamos prácticas socialmente diversificadas de los lugares centrales en las periferias, aunque se observan patrones de consumo según los perfiles sociales. A pesar de que cada segmento social tienda a privilegiar ciertos tipos de lugares para ciertos tipos de prácticas, cada categoría de lugar central identificado (excepto las pequeñas centralidades populares que se asimilen a centros de barrios) es frecuentado por una mezcla social. Esta mezcla varía según los lugares como lo muestra este cuadro de la estratificación social de los clientes de 3 centros comerciales de las zonas de estudio.

\section{Cuadro 1 - Estratificación social de los clientes de tres centros comerciales}

\begin{tabular}{|c|c|c|c|}
\hline $\begin{array}{l}\text { Estrato } \\
\text { social }\end{array}$ & $\begin{array}{l}\text { CC CentroSuba } \\
\text { (Suba) }\end{array}$ & CC Subazar (Suba) & CC Plaza Milenio (Patio Bonito) \\
\hline 1 & $0,00 \%$ & $2,00 \%$ & $25,00 \%$ \\
\hline 2 & $30,00 \%$ & $46,00 \%$ & $60,00 \%$ \\
\hline 3 & $60,00 \%$ & $46,00 \%$ & $15,00 \%$ \\
\hline 4 & $10,00 \%$ & $5,00 \%$ & $0,00 \%$ \\
\hline
\end{tabular}

Fuente: entrevistas con gerentes de los centros comerciales CentroSuba (20/03/2009), Subazar (28/03/2009) y Plaza Milenio (15/04/2009) y documentos internos.

Las características sociales del entorno y la presencia, o no, de marcas explican estas diferencias. Sin embargo, hay que recordar que las poblaciones que frecuentan estos lugares no son únicamente las que compran allí: esta dimensión no aparece en estos datos.

En las periferias, se observan a nivel comercial formas de complementariedad entre los distintos lugares con atributos de centralidad, que ofrecen diferentes tipos de comercios. Según sus necesidades y sus limitaciones económicas (que no podemos tratar en este artículo), la gran mayoría de los habitantes usa varios de estos lugares. Los espacios comerciales no son fragmentados. La tendencia hacia el consumismo en los grandes centros comerciales es fuerte y se acentúa con la llegada de nuevos residentes de un estatus más alto. Pero la gran mayoría de los residentes periféricos sigue frecuentando las tiendas de barrios y las centralidades populares que rinden un servicio muy importante en la cotidianidad para satisfacer las necesidades básicas pero que también impulsan la dinámica del consumismo. La consolidación de lugares con atributos de centralidad en las periferias y las interacciones entre ellos hacen surgir espacios complejos que llamamos nuevas centralidades periféricas. 


\section{2. Las centralidades periféricas como lugares de esparcimiento}

Después del acceso a los comercios, lo que resaltan las personas entrevistadas es la mejora de acceso a los sitios de esparcimiento, haciendo referencia a todos los lugares que son frecuentados durante el tiempo libre. «Hay más sitios para ver, para visitar» comentaron muy a menudo los entrevistados. Pero esta percepción se refiere a una gran variedad de prácticas. Se necesita entonces reconstruir las prácticas de esparcimiento que, igual que las prácticas comerciales, se dan en una pluralidad de lugares dentro de las zonas de estudio. ¿A qué tipo de esparcimiento acceden realmente los habitantes de las periferias? En el formulario, teníamos preguntas para identificar precisamente los lugares frecuentados para cada una de estas actividades: paseo, diversión, cultura, deporte, encuentro familiar o con amigos, reuniones sociales, salidas de noche, helado o café, «vitrinear».

Como primera aproximación, se tiene que subrayar la débil realización de ciertas actividades. Las actividades culturales fueron mencionadas una sola vez: una profesora de un colegio del sector de Patio Bonito dijo frecuentar la biblioteca del Tintal. El acercamiento espacial de los recursos culturales, mediante la construcción de esta biblioteca grande (pero mal insertada a su entorno urbano), no ha causado usos reales importantes. La receta exitosa de la biblioteca del Tunal o de las bibliotecas grandes de Medellín no se ha reproducido aquí: no se observan flujos tan importantes. Por más que algunas asociaciones barriales realizan esfuerzos grandes para fomentar las prácticas culturales, en su mayoría los habitantes no suelen frecuentar tampoco este tipo de escenarios culturales. Por otro lado, los encuentros con familiares y con amigos se realizan casi siempre en la casa, y solo los jóvenes salen a veces de noche, generalmente a otros sitios de la ciudad, o en los centros comerciales en Suba (Subazar en particular). Sin embargo, los barrios de origen informal presentan una actividad nocturna a veces importante. Puede ser que la pregunta fuera sesgada en la medida en que salir supone también salir del barrio. No tenemos entonces información sobre este aspecto, que en las observaciones se reveló sobresaliente. Otra pregunta apuntaba a las actividades de diversión, que son realizadas únicamente por algunos hombres de edad, en los barrios (billares, tejo) o por los niños, en los centros comerciales (juegos mecánicos). En cuanto al paseo, se presenta como una actividad que sólo se realiza afuera de la ciudad. Se trata principalmente de las visitas a los familiares en las regiones de origen, una o pocas veces al año. Por su parte, las personas de ingresos más elevados suelen ir de manera más regular a su finca propia o a la finca de conocidos.

Dentro de las actividades con más éxito, se tienen que subrayar las deportivas que la mitad de las personas mencionaron practicar, en su mayoría en el barrio (caminar, percibido como una actividad deportiva para muchos), en la ciclovía21

21 La ciclovía es un escenario urbano organizado todos los domingos por la mañana por la alcaldía mayor de Bogotá que cierra a la circulación las principales vías de la capital para su disfruto recreativo por los ciudadanos. 
o en los parques barriales y zonales como el Polideportivo de la Gaitana, ubicado en un sector popular del suroccidente de Suba. Este parque es un ejemplo de equipamiento público apropiado por los residentes de los barrios cercanos que los fines de semana practican allí aeróbicos (clases gratuitas organizadas por la alcaldía), fútbol y microfútbol en las canchas abiertas, patinaje de velocidad, etc. La cercanía a una iglesia muy concurrida y a una concentración apreciable de equipamientos, organizaciones sociales y comercios, es un elemento clave que explica la vitalidad de la centralidad popular de la Gaitana, que alcanza a polarizar un conjunto de barrios. De las entrevistas, podemos inferir igualmente que los gimnasios privados, que tienen tanto éxito en otras partes de la ciudad, son en las periferias reservados a una minoría, a pesar de su incremento en los centros comerciales (un gimnasio con la única piscina de Suba en el centro comercial Plaza Imperial) y en las centralidades populares. Los centros comerciales proponen también canchas sintéticas con cuota de entrada que son concurridas.

Otra actividad más generalizada es la asistencia a reuniones sociales, pero que se refiere casi exclusivamente a las reuniones religiosas. Aproximadamente la mitad de las personas declararon asistir a misa el domingo en la iglesia del barrio. La religiosidad es uno de los principales vínculos sociales. Al contrario, la escasa participación a las reuniones de las organizaciones comunitarias, que han sido el motor del equipamiento de los barrios de origen informal y de los primeros conjuntos formales, es la señal de un cambio profundo en la relación de los ciudadanos con su barrio como espacio de identidad y de movilización colectiva. Tampoco se frecuentan las reuniones sindicales o políticas. Estos comportamientos son la señal de que los habitantes actuales de las periferias bogotanas presentan modos de vida mucho más individualistas que las generaciones anteriores. Los espacios de la vida cotidiana se están ampliando desde lo barrial a lo que podríamos llamar lo zonal y que corresponde a la escala de las centralidades periféricas que definimos como un conjunto de lugares con atributos de centralidad.

Este aspecto se observa también a partir del hecho de que dentro de las actividades de esparcimiento realizadas fuera de la casa la que es, sin lugar a dudas, la más generalizada es ir a «vitrinear», actividad que se realiza exclusivamente en los centros comerciales, con una preferencia por los nuevos, que son más grandes. Las personas que tienen ingresos muy bajos son las únicas que han declarado no practicarla. Este tipo de actividad se realiza mayoritariamente en familia los fines de semana, por hogares de recursos bajos o medios. Se acompaña pocas veces de la compra efectiva en los almacenes del centro comercial, pero casi siempre de la toma de un helado, una bebida o un café compartido en familia, a veces de un almuerzo o de una ida al cine. Los padres de familia aprecian los pasillos amplios en los cuales los niños, según ellos, pueden caminar en forma segura, a diferencia de la calle. Otro motivo de su atractivo son los eventos, a veces gratuitos, organizados por la administración de los centros comerciales: conciertos, desfiles de moda, animaciones para los niños. El centro comercial Tintal tuvo por ejemplo mucho éxito al reconstruir, en junio 2009, una nave pirata de tamaño real encallada sobre una playa en la cual una multitud de niños, mediante el pago del arriendo de la pala, podían hacer castillos de arena. 
Estas actividades conforman el universo cultural de muchas familias bogotanas de las periferias. Las nuevas centralidades periféricas se construyen así cada vez más como lugares de esparcimiento que tienden a dominar la oferta cultural en estas zonas. Las centralidades populares y barriales, cuando existen y cuando presentan un cierto grado de inversión pública, son el lugar de actividades sociales, religiosas y deportivas. Pero cada vez más, las familias de los sectores periféricos, que no se encuentran en posición de marginalidad social, disfrutan de su tiempo libre en los grandes centros comerciales, que se presentan más como centros de esparcimiento que como centros de compras, una dimensión aún más fuerte para las familias de clase baja.

\section{3. Acceso a los servicios administrativos y a la salud: el papel de las centralidades periféricas}

Las nuevas configuraciones territoriales periféricas juegan un papel importante en la mejora del acceso a los servicios administrativos. En las entrevistas, notamos que habitantes de todos los perfiles sociales acuden a los centros administrativos llamados Supercade, que fueron construidos por la alcaldía al frente de los terminales de Transmilenio, y que agrupan varias entidades públicas. Además, los centros comerciales ofrecen servicios bancarios y de telefonía que brindan servicio a la comunidad. Según las palabras de su gerente22, el centro comercial Plaza Milenio se volvió el «centro financiero» de Patio Bonito porque comprende cinco oficinas bancarias, así como un punto de atención de la multinacional de telefonía Telmex. Eso explica que ciertas personas de clase media de los alrededores lo frecuentan a pesar de su imagen popular.

Debido al incremento de las inversiones en el sector social desde el año 2004, se observan cambios en la cobertura de salud. Los entrevistados hacen énfasis en el aumento de los puestos de salud en los barrios. Las personas de más bajos recursos son aquellas que perciben las mejoras en el acceso a la salud: frecuentan los CAMI de la Gaitana, Suba Salitre, San Carlos y Patio Bonito o los hospitales de Suba y de Kennedy (que va a ser desdoblado por el nuevo hospital del Tintal en 2011). Estas instalaciones públicas son cercanas a los lugares de residencia y destinadas a atender en prioridad a las poblaciones que benefician del Sisben, es decir los subsidios del Estado para la salud otorgados a los más desfavorecidos. Las personas que pueden pagar los servicios de una EPS (entidades promotoras de salud, privadas en su mayoría) están asignadas al puesto de salud de su EPS, que generalmente está más lejos del domicilio.

Para la educación, el impacto de las centralidades periféricas como tales no existe realmente ya que los nuevos colegios, públicos y privados, están dispersos en los espacios residenciales, y que todavía no se ha construido una universidad en los dos sectores de estudio. Sin embargo, gracias a las inversiones importantes de la alcaldía

22 Entrevista con Eduardo Durán, gerente del centro commercial Milenio Plaza, 15/04/2009. 
en el sector educativo, se ha mejorado globalmente el acceso de los más pobres a la educación pública en estos sectores, a pesar de múltiples denuncias sobre la mala calidad del sistema educativo público. Las clases medias, que en su gran mayoría acuden a la educación privada, suelen escoger el colegio de los niños por el prestigio percibido de los establecimientos, lo que supone a veces movilidades pendulares de los niños muy largas, ya que muchos colegios se encuentran en el norte de la ciudad, a veces en la parte rural. En este sentido, la cercanía a una oferta educativa de calidad constituye un motivo importante de escogencia residencial para las familias de clase media que se instalan en Suba-Pueblo.

Se puede afirmar que las centralidades periféricas juegan un papel en el mejoramiento del acceso real de los individuos de escasos recursos a algunos bienes básicos como la recreación y la salud. No obstante, las actividades que se consolidan en los nuevos lugares de centralidad son principalmente de naturaleza comercial, y entonces excluyentes para los más pobres. La proliferación de las actividades económicas en estos sectores de la ciudad responden a diversas lógicas, entre otras el «rebusque», para las personas que buscan consolidar una actividad de sobrevivencia, o la penetración de los mercados periféricos que tienen un gran potencial de «maduración», para las firmas multinacionales y los grandes inversionistas. Sin embargo, la predominancia de lo comercial en las periferias, en todas sus formas, contribuye a fortalecer la dimensión mercantil en la manera como los habitantes se relacionan con la ciudad. La complejidad de las organizaciones espaciales permite que se mezclan prácticas espaciales con grados diversos a nivel individual. Se observan allí prácticas que se asemejan con las que se observan en los sectores de clase media de la ciudad y prácticas de un orden más popular, determinadas tanto por limitaciones económicas como por costumbres y componentes culturales.

Más allá del acceso a los recursos urbanos, el estudio de las prácticas espaciales debe ser movilizado para interrogar la manera en que las centralidades periféricas, por más comerciales que sean, constituyen nuevos referentes urbanos. De nuestras entrevistas, se destaca que una parte de los habitantes de estos espacios periféricos, sin mucha calidad urbana, no conocen el centro de Bogotá. Por ésta y otras razones, la capacidad de las centralidades periféricas a constituirse como lugares de identidad es un reto grande para satisfacer las necesidades de orden simbólico de los ciudadanos.

\section{CENTRALIDADES PERIFÉRICAS E INTEGRACIÓN SIMBÓLICA}

Ya lo hemos mencionado, los cambios ocurridos en los sectores de estudio son muy valorizados por los transeúntes y habitantes entrevistados. No obstante, es significativo que al preguntar sobre el apego con los lugares centrales, nuevos o antiguos, de Suba-Pueblo o de Patio Bonito-Tintal, los entrevistados responden de manera mucho más matizada. Más de la mitad de los entrevistados no tienen apego por los nuevos sectores centrales, aunque los visitan y disfrutan de la cercanía de los servicios que estos prestan. Existen así dos registros de relación con 
los lugares: lo visible y lo íntimo. Lo «bonito» es agradable, pero esta percepción no es suficiente para que todos generan un sentido de pertenencia.

A partir de un cuestionario sobre los lugares frecuentados en toda la ciudad para cada tipo de actividad, y a partir de una pregunta abierta sobre la identificación del «lugar central»23 de los individuos, intentamos restituir las escalas de las territorialidades cotidianas. Con este propósito, se trata de evaluar la capacidad de las centralidades periféricas a transformarse en nuevos espacios de identificación de los ciudadanos.

\section{1. Primer nivel de territorialidad: la casa-refugio}

Una primera categoría de personas no valora ningún lugar específico en la ciudad, sino su casa. Se trata de personas de bajos o muy bajos recursos, principalmente mujeres cabezas de familia. Casi nunca salen de Bogotá. Frecuentan las plazas de mercado barriales y las centralidades populares para todas sus compras. A veces pueden desplazarse lejos en la ciudad hasta un sitio conocido para conseguir una cosa más económica. No tienen ningún tipo de actividad de esparcimiento excepto asistir a misa en la iglesia del barrio, y para los más jóvenes, «vitrinear» a veces en los centros comerciales y salir por la noche en el barrio. Estas personas perciben el barrio con indiferencia o de manera negativa para quejarse de la inseguridad. Los lugares de trabajo, que pueden estar lejos (en el norte por ejemplo para una señora empleada doméstica), son percibidos con mucha exterioridad. Se va allá y se regresa a casa, nada más. Estas personas son indiferentes a la ciudad en general y se concentran sobre la esfera familiar, sobre la casa que les sirve de refugio.

\section{2. Segundo nivel de territorialidad: el barrio como recurso social}

Hombres solteros y personas mayores, de bajos recursos y que llevan mucho tiempo viviendo en el mismo sitio, parecen considerar el barrio como punto nodal de sus vidas. Compran su alimentación en los supermercados del barrio o en las plazas, la ropa en las centralidades populares pero también en los centros comerciales. En el barrio, frecuentan la iglesia, los escenarios deportivos abiertos y sobre todo los lugares tradicionales de diversión (tejo, billares). Tienen un apego al barrio por cuestión de costumbre y porque les ofrece todos los servicios que necesitan: «amigos, deporte, transporte», según un entrevistado. Esta relación fuerte al barrio no excluye paseos por los pueblos cercanos a Bogotá, y la frecuentación de otros sitios en la ciudad, como el centro a donde les gusta ir de manera puntual.

23 El «lugar central» era descrito para los entrevistados como el lugar que «tiene una particular importancia para ellos, porque es familiar, porque es donde se pasan muchas cosas que son importantes para ellos, porque saben que pueden encontrar muchas cosas o gente allá, porque se sienten un poco como en su casa». 


\section{3. Tercer nivel de territorialidad: las «centralidades populares», lugares diversos y familiares a la vez}

Las personas que identifican las «centralidades populares» como el lugar más importante para ellas son sobre todo mujeres con familia de bajos recursos, que pueden tener algún grado de estabilidad laboral. Trabajan principalmente en las periferias, usan el transporte público tradicional y a veces poseen un cicla. Compran su mercado en lugares diversificados, incluso los hipermercados de cadena, pero la ropa principalmente en las «centralidades populares». Les gustan «vitrinear» en los centros comerciales, pero toman helado o café en el barrio o las «centralidades populares». Como actividades de tiempo libre, frecuentan la iglesia y los hombres se divierten en el barrio. De vez en cuando, salen de paseo a los municipios cercanos a Bogotá. Les gustan las centralidades populares por el comercio, la sensación de «tener todo cerca», el ambiente, la familiaridad con los lugares, y la presencia del transporte público tradicional. Al contrario, el barrio está asociado a la familia, a la tranquilidad, a veces a la inseguridad. Estas personas tienen movilidades restringidas a ciertos barrios que polarizan las «centralidades populares», o extendidas hacia sectores amplios en donde se mueven con mucha facilidad (todo Patio Bonito-Tintal o todo Suba-Pueblo por ejemplo). Estas últimas personas tienen cierto apego a los «nuevos sectores centrales» pero los consideran como una pieza dentro de un territorio más abarcador.

\section{4. Cuarto nivel de territorialidad: los centros comerciales antiguos, por fidelidad y costumbre}

Son más diversas socialmente las personas que reconocen los centros comerciales antiguos de Suba como su «lugar-central». Algunas son de estrato 3. También son más diversificadas sus formas de movilidad (con más importancia del Transmilenio, de los taxis y del carro particular) y sus prácticas de compras. Frecuentan varios centros comerciales, antiguos o recientes. Realizan pocas reuniones sociales y religiosas, pocas actividades deportivas y pocas actividades de diversiones (excepto los hombres en el barrio). Lo atractivo de los centros comerciales antiguos es la cercanía, la variedad y sobre todo lo bonito. Ofrecen igualmente un espacio para escaparse del barrio en caso de una percepción negativa de éste. Estas personas se mueven en toda la localidad de Suba pero también en otras partes de la ciudad. A pesar de frecuentar también los nuevos centros comerciales, no tienen apego por ellos: por costumbre, se sienten más a su gusto en los antiguos y en sus alrededores.

\section{5. Quinto nivel de territorialidad: los «nuevos sectores centrales», la atracción de la modernidad}

Los que construyen sus territorialidades a partir de los «nuevos sectores centrales» son personas recién llegadas en las periferias y personas arraigadas que son 
jóvenes o que tienen percepciones negativas de sus espacios de vida tradicionales. Ejemplo de esto es una señora que comentó:

«tengo apego por el centro de Suba, por la imagen de pueblo, pero eso se está acabando. Uno se acostumbra y me gusta ir al Plaza Imperial, que es más comercial. El centro es más para visitar con mi nieta».

Estas personas son de estrato bajo o medio. Sus modos de desplazamientos y sus prácticas de compras son muy diversificados pero frecuentan más el centro de Bogotá que las centralidades populares periféricas. Cuando «vitrinean» en los centros comerciales, toman allá un helado o un café y realizan actividades, como ir al cine o mirar los eventos. Se dedican a actividades en otros lugares de la ciudad, privados (gimnasios) o públicos (ciclovía), pero no en su barrio. Frecuentan otros centros comerciales de la ciudad, por gusto o por cercanía al trabajo. Les gustan los nuevos sectores centrales por la facilidad de acceso (cercanía) y la variedad de bienes y servicios ofrecidos, sobre todo para divertirse. Pero una proporción significativa reconoce visitar estos espacios sin tener apego por ellos. Como para otras categorías de personas, el barrio es un espacio estrictamente residencial. Al respecto un entrevistado comentó: «El barrio es el sitio del existir, del vivir simplemente, no tiene distracciones ni eventos». Y otro: «El Tintal (=el centro comercial Tintal) es los fines de semana, el barrio es todos los días». Estas nuevas formas de territorialidad en las periferias conllevan la ampliación de los espacios de vida.

\section{6. Otras territorialidades}

El centro de Bogotá constituye un lugar más de identificación para ciertas personas de distintos perfiles sociales. Para ellas, el centro es un lugar simbólico o un lugar frecuentado, generalmente una vez por semana. Algunos frecuentan también los nuevos sectores centrales pero sin mucho apego. Finalmente, hay algunas personas que hacen énfasis sobre otros tipos de lugares-referentes: la iglesia que suelen frecuentar en otra parte de la ciudad o su municipio de origen.

En esta encuesta, se destacan las pocas menciones del centro fundacional de Suba como lugar de identidad. El centro del pequeño pueblo sumergido por las olas de urbanizaciones de estas últimas décadas se ha vuelto un espacio institucional de segundo orden. Para sus trámites frecuentes, los subeños necesitan sobre todo acudir al Supercade cerca al Portal de Suba (en el «nuevo sector central») o a los servicios administrativos a nivel distrital, en otras partes de la ciudad. La alcaldía menor de Suba intenta dar al centro fundacional una dimensión cultural al organizar conciertos y eventos en el parque. Pero por ahora, estas experiencias han sido muy limitadas. El centro fundacional es un centro de memoria que solo los antiguos residentes recuerdan. No es un centro de la cotidianidad, ni tampoco un centro simbólico para la inmensa mayoría de la actual población de la localidad. Las centralidades periféricas, conformadas por una pluralidad de lugares con atributos de centralidad, son ahora referentes urbanos para la mayoría de los habitantes de la ciudad periférica. Están apropiadas por prácticas múltiples, 
cotidianas o semanales (caso de los «nuevos sectores centrales» que conocen una gran afluencia los fines de semana). Sin embargo, el hecho de que sean intensamente visitadas no garantiza que conforman espacios de identidad para los ciudadanos. La modernidad de los «nuevos sectores centrales» atrae, sobre todo las nuevas poblaciones de clase media que ven en su presencia un argumento funcional para instalarse en las periferias, a pesar de un desconocimiento y de un miedo del entorno urbano (que ahora pueden evitar). Pero las centralidades más antiguas (centralidades populares o pequeños centros comerciales) conservan su facultad de dar sentido de pertenencia a las poblaciones arraigadas, de clase baja o media baja. No obstante, las franjas socialmente más marginadas de la población de la ciudad periférica no se apropian ningún tipo de estos lugares y manifiestan formas de repliegue sobre la esfera doméstica.

\section{CONCLUSIÓN}

Las nuevas centralidades surgen y se consolidan en las periferias populares de Bogotá a partir de un cambio de escala de los nuevos establecimientos comerciales y del transporte público, con la llegada del sistema Transmilenio que es masivo y estructurante. A este patrón básico, se suma la construcción reciente de nuevos equipamientos de escala metropolitana (hospitales, bibliotecas) y la proliferación de actividades de índole múltiple (comerciales y de servicios) en los barrios de origen informal, actividades que se concentran en los lugares que hemos llamado «centralidades populares». Estas transformaciones solo fueron posibles por el crecimiento demográfico vertiginoso de estos espacios que alcanzan densidades poblacionales muy elevadas. Al respeto, se tiene que subrayar un modelo de conquista por las clases medias de estos espacios que eran socialmente percibidos como populares. Este modelo se fundamenta sobre una alianza entre los constructores de viviendas (exclusivamente privados, incluso en el caso de las viviendas de interés social) y los promotores de centros comerciales que, en Bogotá, venden sus productos inmobiliarios una vez construidos (es decir que después los promotores no gestionan los centros comerciales y no tienen que asumir los riesgos asociados a su no rentabilidad, al contrario de lo que ocurre en muchos países latinoamericanos). Tanto los constructores de viviendas como los promotores de centros comerciales han aprovechado las inversiones públicas en materia de espacios públicos y transporte para revertir las representaciones de estos espacios y atraer familias con un perfil social superior. Así, la nueva urbanidad periférica se puede interpretar como una estrategia de los inversionistas que tiene una dimensión principalmente inmobiliaria pero que apuesta también a la adecuación de los patrones de consumo de los sectores populares con los de los sectores de clase media a partir de dos mecanismos: la atracción de nuevos residentes de estatus social superior y la penetración paulatina de los mercados populares sustentada por el efecto de masa.

El análisis de las prácticas socio espaciales que se dan en estos espacios nos revela que estos procesos no se acompañan de una segmentación social de los 
lugares frecuentados. Al igual que Duhau \& Giglia (2007) para el caso del área metropolitana de Ciudad de México, hemos encontrado una gran diversificación de las prácticas espaciales. No hay compartimentación de los espacios de vida entre clases medias y clases populares a pesar de la existencia de una fuerte segregación residencial y de comportamientos socialmente muy determinados. Las diferencias sociales se notan más en las modalidades y en la intensidad de la apropiación de los lugares que en formas exclusivas de apropiación. Por estas razones, se destaca la necesidad de pensar las centralidades periféricas como el conjunto de los lugares con atributos de centralidad, y no solamente como lo que hemos denominado los «nuevos sectores centrales», en torno a los grandes centros comerciales recientes. Los habitantes de las periferias construyen sus territorialidades a la escala más amplia de este conjunto de lugares diversos y cercanos, que tienen distintas lógicas, y de los cuales pueden aprovechar las complementariedades según diferentes modalidades.

Ahora bien, la dimensión mercantil es la que predomina en la manera cómo los habitantes se relacionan con estos lugares que conforman sus espacios de vida. Y el acceso al consumo es necesariamente desigual, a pesar de que se haya mejorado la satisfacción de las necesidades básicas de las poblaciones de más bajos recursos. Las inversiones públicas en salud y educación han contribuido en eso igualmente, pero hemos mencionado el carácter dual de los sistemas educativos y de salud en Colombia. También, hemos mostrado cómo las centralidades periféricas, y sobre todo los «nuevos sectores centrales», no cristalizan identidades fuertes. A pesar de la valorización casi generalizada de los cambios «visibles», los procesos de construcción simbólica de nuevos referentes urbanos no son tan evidentes. En el marco de la planeación urbana y del diseño de políticas urbanas, es preciso entonces reflexionar acerca de si la integración por el consumo y el esparcimiento puede servir de integración a la ciudad.

Se necesitaría volver a pensar en qué medida las centralidades periféricas pueden mejorar el acceso a la ciudad de los habitantes de bajos recursos de las periferias para cumplir con el objetivo enunciado de equidad territorial. Nos parece que existe tres grandes retos en este proceso :

- Diseñar una verdadera política de descentralización del empleo que por ahora es inexistente. La implementación del sistema de transporte masivo, si bien acerca lugares de empleo y lugares de residencia, reproduce la estructura inequitativa de la ciudad y tiene sus límites, que se perciben cada vez con más fuerza en Bogotá, a punto de colapsar por el caos vehicular.

- Invertir aún más en una oferta de servicios públicos de calidad, tanto de nivel metropolitano (universidades, centros culturales...), como de nivel local en las centralidades populares o en los barrios.

- Regular fuertemente la valorización del suelo de estos sectores. Es un tema que no hemos abordado en este artículo pero que merece particular atención porque los procesos de revitalización asociados a grandes proyectos urbanos se acompañan muy a menudo de fenómenos de elitización que conllevan exclusión. 


\section{Referencias citadas}

ALBA, J., 1998 - El surgimiento de la centralidades en les periferias urbanas de Santa Fé de Bogotá, tesis de maestría en urbanismo; Bogotá: Universidad Nacional de Colombia.

ALCALDÍA MAYOR DE BOGOTÁ, 2004 - Plan de Ordenamiento de Santa Fé de Bogotá, Decreto distrital 190 (compilación de los decretos 619 de 2000 y 469 de 2003).

AGUILAR, A., G., 2002 - Las megaciudades y las periferias expandidas. EURE, Revista Latinoamericana de Estudios Urbanos y Regionales, Vol. XXVII (85): 121-149.

ASCHER, F., 1995 - Metapolis ou l'avenir des villes, 345 pp.; París: Odile Jacob.

BORJA, J., 2003 - Ciudad y Planificación. La urbanística para las ciudades de América Latina. In: La ciudad inclusiva (J. Balbo, R. Jordán, \& D. Simioni, eds.): 313 pp.; Santiago de Chile: Naciones Unidas-CEPAL, Cooperazione Italiana.

BORJA, J. \& CASTELLS, M., 1997 - Local y global: la gestión de las ciudades en la era de la información, 418 pp.; Madrid: Taurus.

BORSDORF, A., BÄHR, J. \& JANOSCHKA, M., 2002 - Die Dynamik stadtstrukturellen Wandels in Lateinamerica im Modell der lateinamerikanischen Stadt. Geographica Helvetica, 57 (4): 300-310. Cuadernos de la CEPAL n. ${ }^{\circ}$ 88,

CAPRON, G., 1998 - Les centres commerciaux à Buenos Aires. Les nouveaux espaces publics de la ville de la fin du XXe siècle. Annales de la Recherche Urbaine, $\mathbf{n} .^{\circ} \mathbf{7 8}$ : 55-63.

CHAMBOREDON, J. \& LEMAIRE M., 1970 - Proximité spatiale et distance sociale. Les grands ensembles et leur peuplement. Revue française de sociologie, $\mathbf{n} .^{\circ} \mathbf{1}: 3-33$.

CORNEJO PORTUGAL, I. \& BELLÓN CÁRDENAS, E., 2001 - Prácticas culturales de apropiación simbólica en el centro comercial Santa Fé. Convergencia, n. ${ }^{\circ}$ 24: 6786; México: Universidad Autonoma del Estado de México.

DANE, 1993 - Censo general de Colombia; Bogotá.

DANE, 2005 - Censo general de Colombia; Bogotá.

DE MATTOS, C., 1999 - Santiago de Chile, globalización y expansión metropolitana: lo que existía sigue existiendo. EURE, Revista Latinoamericana de Estudios Urbanos y Regionales, Vol. XXV (76): 29-56.

DEPARTAMENTO NACIONAL DE PLANEACIÓN, 1974 - Ciudades dentro de la ciudad. La política urbana y el plan de desarrollo en Colombia, 121 pp.; Bogotá: Tercer Mundo.

DUHAU, E. \& GIGLIA, A. 2007 - Nuevas centralidades y prácticas de consumo en la Ciudad de México: del microcomercio al hipermercado. EURE, vol. 33, n. ${ }^{\circ} \mathbf{9 8}$ : 77-95.

GARREAU, J., 1991 - Edge City, Life on the New Frontier; New York: Anchor Books.

GUTIÉRREZ, D., 2008 - Determinantes de la localización del empleo urbano, el caso de Bogotá D.C.; Bogotá: Universidad de los Andes. Tesis de maestría en economía.

HURTADO, A., 2008 - Portales de Transmilenio: revitalización de espacios e integración social urbana en Bogotá D.C.; Bogotá: CIDER, Universidad de los Andes. Tesis de maestría de planificación y administración del desarrollo regional.

LAUTHIER, B., 2004 - L'économie informelle dans le tiers-monde, 121 pp.; París: La Découverte.

LINK, F., 2009 - De la policentralidad a la fragmentación en Santiago de Chile. Revista Centro- $h, \mathbf{n}^{\circ}$ 2: $13-24$. Policentralidad en la ciudad actual, OLACCHI.

http://www.revistacentro-h.org/articulos.php?id=2 
LEFÈBVRE, H., 1974 - La production de l'espace, 485 pp.; París: Anthropos.

ORDOÑEZ MONTOYA, F., 1992 - El barrio del Rincón-Escuela en Suba, proceso de formación y formas organizativas; Universidad Santo Tomás. Tesis de grado.

SASSEN, S., 1991 - The Global city: New York, London, Tokyo; Princeton: Princeton University Press.

SCHELOTTO, S., 2009 - La ciudad de Montevideo: ¿una metrópoli policéntrica? Revista Centro- $h, \mathbf{n}^{\circ}$ 2: 37-46. Policentralidad en la ciudad actual, OLACCHI.

http://www.revistacentro-h.org/articulos.php?id=2

VELTZ, P., 1996 - Mondialisation, villes et territoires, 264 pp.; París: PUF.

VIGNOLI, J. R., 2008 - Movilidad cotidiana, desigualdad social y segregación residencial en cuatro metrópolis de América Latina. EURE, Revista Latinoamericana de Estudios Urbanos y Regionales, Vol. XXXIV (103): 49-71. 